\title{
Características da pastagem de azevém e produtividade de cordeiros em pastejo $^{1}$
}

\section{Ticiany Maria Dias Ribeiro², Alda Lúcia Gomes Monteiro³, César Henrique Espírito Candal Poli $^{4}$, Aníbal de Moraes ${ }^{5}$, Ana Luisa Palhano Silva ${ }^{6}$, Carina Simionato de Barros ${ }^{7}$}

${ }_{1}$ Projeto financiado pelo CNPq.

2 Mestranda do curso de Pós-Graduação em Agronomia - Produção Vegetal da UFPR. Avenida Paraná, 998, apto 1002, Cabral, Curitiba PR - Brasil, CEP: 80.035-130. Bolsista CAPES

${ }^{3}$ Departamento de Zootecnia, SCA, UFPR. Rua dos Funcionários, 1540, Cabral, Curitiba - PR - Brasil, CEP: $800035-050$.

${ }^{4}$ Departamento de Zootecnia, UFRGS.

${ }^{5}$ Departamento de Fitotecnia e Fitossanitarismo, SCA, UFPR.

${ }^{6}$ FIES e UTP

${ }^{7}$ Departamento de Medicina Veterinária - UNIGUAÇU, União da Vitória, PR

RESUMO - Objetivou-se avaliar a produção da pastagem de azevém, a qualidade da forragem e a produtividade animal por área em três sistemas de produção: cordeiros desmamados precocemente, aos 40 dias de idade, e mantidos em pastagem de azevém (Lolium multiflorum Lam.) até o abate; cordeiros sem desmame, mantidos na mesma pastagem de azevém até o abate; cordeiros sem desmame recebendo suplemento (1\% do peso vivo) em creep feeding a partir dos 40 dias de idade. O sistema de pastejo utilizado foi o de lotação contínua com carga animal variável, mantendo-se a oferta de massa de lâminas foliares em $1.000 \mathrm{~kg}$ de MS/ha. A produção média de massa seca da pastagem foi 3.236,6 kg MS/ha, a de lâminas foliares, de $1.008,7 \mathrm{~kg} \mathrm{MS} / \mathrm{ha}$, e a taxa de crescimento do pasto, de 58,38 kg MS/ha/dia. Com cordeiros desmamados, a altura média da pastagem foi de 20,95 cm, significativamente maior que a daquela com cordeiros sem desmame. A massa de inflorescências nas pastagens dos cordeiros desmamados foi superior $(61,7 \mathrm{~kg} / \mathrm{ha})$ quando comparado aos outros sistemas. O sistema de terminação de cordeiros desmamados permitiu maior carga animal (929,74 kg PV/ha) em comparação aos demais, considerando apenas os cordeiros sem suplementação (259,9 kgPV/ha) ou com suplementação em creep feeding (254,3 kgPV/ha) A qualidade da forragem não diferiu entre os sistemas de terminação. A estrutura da pastagem sofreu alterações na ausência das ovelhas, devido à maior seletividade dos cordeiros. O sistema de terminação em pastagem com desmame precoce foi o menos produtivo, em razão do baixo desempenho individual dos cordeiros, por isso, não deve ser recomendado a ovinocultores.

Palavras-chave: ganho por área, massa de forragem, lotação animal, ovinos, relação folha:colmo

\section{Ryegrass pasture characteristics and lamb productivity in grazing}

ABSTRACT - The objective of this study was to evaluate the ryegrass pasture production, forage quality and animal productivity in three sheep production systems: lambs weaned at 40 days of age and finished in ryegrass (Lolium multiflorum Lam.) until slaughter; lambs kept with their dams in the same pasture until slaughter; same treatment, but the lambs were supplemented in $1 \%$ of live weight with concentrate in creep feeding. The grazing method was continuous variable stocking, in order to maintain $1,000 \mathrm{~kg}$ of leaf dry matter per hectare. The mean forage production was 3,236.6 kg DM/ha, the leaf lamina production was $1,008.7 \mathrm{~kg} \mathrm{DM} / \mathrm{ha}$ and the pasture daily growth rate was $58.38 \mathrm{~kg} / \mathrm{ha}$. With weaned lambs, the mean height of pasture $(20.95 \mathrm{~cm})$ was higher when compared to others. The inflorescence production in pastures for weaned lambs (61.7 kg/ha) was higher when compared to other systems. Weaned lambs presented higher animal stocking rate $929.7 \mathrm{~kg} \mathrm{BW} / \mathrm{ha}$, considering only lambs without supplementation (259.9 kgBW/ha) or with creep feeding (254.3 kgBW/ha) The forage quality was not different between systems. The pasture structure changed due to the higher selectivity of lambs without dams in pasture. The productivity of the weaning system was reduced due to lower individual performance of lambs; therefore, this system should not be recommended for sheep breeders.

Key Words: animal stocking, forage mass, gain per area, leaf:stem ratio, sheep 


\section{Introdução}

O planejamento da atividade pecuária em pastagens implica conhecer o padrão de distribuição da massa de forragem ao longo da estação de crescimento, estimar a produtividade de forragem esperada e definir a carga animal de acordo com os ganhos individuais de peso projetados para cada categoria (Freitas et al., 2005).

Farinatti et al. (2006) descreveram que a utilização de pastagens cultivadas de ciclo de inverno-primavera tem sido uma das alternativas para reduzir a carência alimentar durante o período crítico ou de maior exigência nutricional para ovinos.

Entre as possibilidades de corrigir os prejuízos ocasionados pela sazonalidade forrageira, o uso de azevém-anual (Lolium multiflorum Lam.) tem sido bastante indicado para terminação de animais jovens, principalmente no sistema da monta anual, com parição no inverno/primavera. Neste contexto, a região sul do Paraná possui condições de produção de forragem de ótima qualidade que garantem boa oferta aos animais nesse período de elevada demanda nutricional.

Manejar corretamente as pastagens é, sem dúvida, o maior desafio enfrentado pelo produtor, uma vez que muitos fatores interferem diretamente na disponibilidade e qualidade da pastagem, entre eles, a época do ano, as características genéticas da planta, a carga animal, o sistema de produção e a estratégia de manejo de pastagem. No manejo da pastagem, deve-se, ao mesmo tempo, manter área foliar fotossintéticamente ativa e permitir que animais colham grandes quantidades de tecido foliar de alta qualidade (Pedreira et al., 2005), a fim de melhorar a produção forrageira, a eficiência de conversão da forragem, a estabilidade do sistema, o desempenho animal e a produção animal por hectare (Ferreira \& Zanine, 2007). Entende-se, portanto, que o manejo envolve a regulação do consumo de forragem pelos animais por meio de intervenções do homem (Briske \& Heitschmidt, 1991) e requer o entendimento da dinâmica de crescimento das plantas.

Este trabalho é parte de uma linha de pesquisa na qual foram estudados sistemas de terminação de cordeiros em pastagens de verão e inverno, com e sem suplementação. Objetivou-se avaliar a produção da pastagem de azevém, a qualidade da forragem e a produtividade animal por área em três sistemas de produção.

\section{Material e Métodos}

O experimento foi realizado no período de 5 de agosto de 2004 a 7 de janeiro de 2005 na área de Ovinocultura no Centro de Estações Experimentais do Canguiri (CEExC), da
Universidade Federal do Paraná - UFPR, localizada na região metropolitana de Curitiba, em Pinhais-PR, na Área de Preservação Ambiental do Irai, a 2525' Sul e 49 ${ }^{\circ} 8^{\prime}$ Oeste e 915 m acima do nível do mar. O clima é do tipo Cfb, classificação de Köepen, que corresponde ao Clima Subtropical Úmido (Mesotérmico), em índice pluviométrico de $1.500 \mathrm{~mm}$ médios anuais, temperatura mínima média em julho $\left(8,4^{\circ} \mathrm{C}\right)$ e máxima média em fevereiro $\left(26,2^{\circ} \mathrm{C}\right)$.

O solo da área experimental é classificado como Latossolo Vermelho-Amarelo Álico (EMBRAPA, 1999) com textura argilosa, campo subtropical e relevo suave ondulado. A análise de solo da área experimental revelou os seguintes valores médios: $\mathrm{pH}=6,3 ; \mathrm{P}=12,8 \mathrm{mg} / \mathrm{dm}^{3} ; \mathrm{K}=0,14 \mathrm{cmol}_{\mathrm{c}} / \mathrm{dm}^{3}$; $\mathrm{Ca}=7,26 \mathrm{cmol}_{\mathrm{c}} / \mathrm{dm}^{3} ; \mathrm{Ca}^{2}+\mathrm{Mg}^{2}=10,9 \mathrm{cmol}_{\mathrm{c}} / \mathrm{dm}^{3}$; e saturação de bases $72 \%$, considerado adequado ao plantio de azevém.

Em março de 2004, foi realizada a sobressemeadura do azevém (Lolium multiflorum Lam.), a lanço com 30 kg/ha, em área de Tifton 85 (Cynodon spp.), implantada em 2003. Foram aplicados $300 \mathrm{~kg} \mathrm{~N} / \mathrm{ha}$, parcelados em três vezes, nos meses de maio, junho e agosto de 2004. O experimento ocupou uma área de 2,55 ha, subdividida em três piquetes de 0,15 ha e seis piquetes de 0,35 ha, totalizando nove piquetes na pastagem.

O delineamento experimental foi inteiramente casualizado, com três tratamentos e três repetições (piquetes). Os animais foram distribuídos de maneira uniforme de acordo com o peso ao nascer, o sexo e o tipo de parto (simples ou gemelar). Foram utilizados seis cordeiros-teste em cada tratamento, três fêmeas (uma de parto simples e duas de parto gemelar) e três machos (um de parto simples e dois de parto gemelar).

Foram comparados três sistemas de terminação de cordeiros Suffolk em pastagens: cordeiros desmamados precocemente, aos 40 dias de idade, e mantidos em pastagem de azevém (Lolium multiflorum Lam.) até o abate; cordeiros sem desmame na mesma pastagem de azevém até o abate; cordeiros, sem desmame, recebendo suplemento (1\% do peso vivo) em creep feeding a partir dos 40 dias de idade. Os animais foram colocados na área experimental uma semana antes das avaliações para adaptação à cerca elétrica e ao ambiente e, ao início da avaliação, tinham 43 dias de idade e peso vivo médio de $15,7 \mathrm{~kg}$.

Os animais que permaneceram com as ovelhas foram distribuídos em seis piquetes de 0,35 ha e aqueles com desmame, em três piquetes de 0,15 ha, totalizando nove piquetes na pastagem de azevém, cada um correspondendo a uma unidade experimental.

O método de utilização de pastagem foi o de lotação contínua com carga animal variável, com seis cordeirosteste e número variável de reguladores. Os cordeiros-teste 
foram mantidos nos piquetes durante todo o período de avaliação e só foram retirados para o abate ou em caso de óbito, enquanto os reguladores foram utilizados para adequar a carga animal pela técnica put and take (Mott \& Lucas, 1952), mantendo-se a massa seca de lâminas foliares em $1.000 \mathrm{~kg} / \mathrm{ha}$ em todos os sistemas de terminação para não limitar o consumo. Os ajustes de carga animal foram realizados a cada 14 dias.

Para as avaliações da pastagem, as colheitas foram realizadas a cada 14 dias e o corte da pastagem foi realizado rente ao solo. A taxa de crescimento da pastagem foi mensurada pela técnica do triplo emparelhamento (Moraes et al., 1990) utilizando-se três gaiolas de exclusão. Além das duas amostras da pastagem colhidas na realização do triplo emparelhamento, existia uma terceira amostra, colhida aleatoriamente por piquete com o intuito de aumentar a precisão da avaliação. A taxa de acúmulo foi obtida pela diferença entre a massa seca da amostra colhida dentro da gaiola na data da amostragem e a massa seca da amostra colhida fora da gaiola na data da amostragem anterior, dividida pelo número de dias entre as avaliações (14 dias). A produção acumulada de forragem foi calculada pela soma da massa total de forragem acumulada mais a massa residual colhida no primeiro dia de avaliação.

As amostras colhidas eram utilizadas para obtenção da massa de forragem e da composição botânica da pastagem. Após o corte, as amostras foram armazenadas em sacos plásticos, identificadas e enviadas ao Laboratório de Fitotecnia da Universidade Federal do Paraná. Uma subamostra da massa verde total colhida foi utilizada para caracterização da pastagem, após separação manual de lâminas foliares, colmos e bainhas, inflorescências e material morto das duas espécies azevém e Tifton 85 e de outras gramíneas, outras leguminosas e plantas invasoras. Posteriormente, as frações de subamostras e o restante da amostra eram acondicionadas separadamente em sacos de papel e levadas à estufa de ventilação forçada a $65^{\circ} \mathrm{C}$, durante 48 horas, até peso constante. Depois de secas, as amostras eram retiradas e pesadas em balança de precisão de 1 grama, para determinação das massas de forragem, de lâminas foliares, colmo + bainha, inflorescência, material morto, azevém e Tifton-85 em kg/ha. Com esses dados, foi possível calcular a relação folha:colmo, dividindo-se o valor de massa de lâminas foliares por massa colmo + bainha.

A altura do dossel forrageiro foi mensurada utilizando-se bastão medidor (sward stick), segundo Barthram (1986). Como altura do pasto considerou-se a altura média (cm) do toque do bastão na primeira folha encontrada no dossel. Em cada avaliação, foram amostrados 70 pontos aleatórios por unidade experimental.
Amostras de pasto foram colhidas manualmente, simulando o pastejo do cordeiro, segundo a metodologia denominada hand plucking (Burms et al., 1989), para avaliação da qualidade da pastagem. As amostras, contendo aproximadamente $500 \mathrm{~g}$ de forragem de cada repetição, foram secas em estufa de $65^{\circ} \mathrm{C}$ por 48 horas e moídas. As análises químicas foram realizadas no Laboratório de Nutrição Animal da UFPR para determinação dos valores brutos (totais) de: proteína bruta $(\mathrm{PB})$, cálcio $(\mathrm{Ca})$ e fósforo $(\mathrm{P})$, conforme descrito por Silva (1990), e fibra em detergente neutro (FDN) e fibra em detergente ácido (FDA), conforme proposto por Van Soest et al. (1991). Para estimativa dos nutrientes digestíveis totais, foram utilizadas fórmulas descritas por Kearl(1982).

Os animais eram pesados a cada 14 dias para obtenção do ganho médio diário. A carga animal foi calculada com o peso vivo médio dos animais em cada período, dividido pela área da unidade experimental e expresso em $\mathrm{kg} / \mathrm{ha}$ de peso vivo. A carga animal nos sistemas com cordeiros e cordeiros + ovelhas foi obtida separadamente. O número de animais por área foi calculado por média ponderada utilizando o número total de cordeiros por repetição dividido pelo número de dias na área. O ganho de peso por área foi obtido multiplicando-se o ganho médio diário dos cordeiros-teste pelo número de animais/dia/ha.

Foi realizada análise de variância, com o efeito fixo dos sistemas de alimentação para os resultados significativos, segundo o modelo matemático: $\mathrm{Y}_{\mathrm{ij}}=\mu+\mathrm{S}_{\mathrm{i}}+\mathrm{e}_{\mathrm{ij}}$, em que: $\mathrm{Y}_{\mathrm{ij}}=$ valor da variável estudada no indivíduo j no sistema de produção i; $\mu$ = média geral; $S_{i}=$ efeito do sistema de produção i (de 1 a 3); $e_{\mathrm{ij}}=$ erro aleatório associado a cada observação. As médias foram comparadas pelo teste Duncan a 5\% de significância utilizando-se o programa computacional Statistic, versão 5.0.

\section{Resultados e Discussão}

A massa de forragem não diferiu entre os sistemas de terminação (média 2.900,8 kg/ha de MS) e esteve acima do valor sugerido por Carvalho et al. (2004a), de $2.000 \mathrm{~kg} / \mathrm{ha}$ de MS, para não limitar o consumo dos animais e para máximo desempenho de ovinos em pastagens de clima temperado (Tabela 1).

Não houve diferença significativa para massas de lâminas foliares $(\mathrm{P}=0,81)$, colmo + bainha $(\mathrm{P}=0,35)$, azevém $(\mathrm{P}=0,45)$, tifton 85 ( $\mathrm{P}=0,93)$ e material morto $(\mathrm{P}=0,13)$. Pelo erro-padrão da média, a variação na massa de folhas e de colmos variou mais na pastagem com cordeiros desmamados que naquela com ovelhas, o que pode representar uma alteração na forma estrutural da pastagem, relacionada às diferenças nas 
Tabela 1- Características da pastagem de azevém utilizada por cordeiros em três sistemas de terminação

\begin{tabular}{|c|c|c|c|c|c|c|}
\hline Item & $\begin{array}{c}\text { Cordeiros } \\
\text { desmamados }\end{array}$ & $\begin{array}{c}\text { Erro-padrão } \\
\text { da média }\end{array}$ & $\begin{array}{c}\text { Cordeiros sem } \\
\text { desmame }\end{array}$ & $\begin{array}{c}\text { Erro-padrão } \\
\text { da média }\end{array}$ & $\begin{array}{l}\text { Cordeiros em } \\
\text { creep feeding }\end{array}$ & $\begin{array}{c}\text { Erro-padrão } \\
\text { da média }\end{array}$ \\
\hline Massa de forragem (kg/ha) & $2.900,3$ & 399,8 & $2.815,0$ & 441,3 & $2.987,1$ & 303,6 \\
\hline Lâminas foliares (kg/ha) & $1.181,7$ & 374,0 & 807,5 & 78,7 & 724,9 & 49,9 \\
\hline Colmo + bainha (kg/ha) & 830,9 & 101,3 & 828,7 & 79,2 & 762,1 & 74,9 \\
\hline Azevém (kg/ha) & $1.009,2$ & 38,5 & 911,9 & 57,8 & 921,2 & 121,3 \\
\hline Tifton 85 (kg/ha) & 663,6 & 267,1 & 540,4 & 173,8 & 557,7 & 40,7 \\
\hline Inflorescência (kg/ha) & $61,7 \mathrm{a}$ & 15,3 & 13,3b & 10,3 & $10,8 b$ & 4,2 \\
\hline Altura (cm) & $20,95 a$ & 0,2 & $17,5 b$ & 0,6 & $16,3 b$ & 0,8 \\
\hline
\end{tabular}

Médias seguidas de letras diferentes na mesma linha diferem $(\mathrm{P}<0,05)$ pelo teste Duncan.

estratégias de consumo de forragem entre cordeiros e ovelhas. Essa alteração na estrutura também pode ser comprovada pela diferença da altura na pastagem. A massa seca de inflorescência foi maior nos piquetes dos cordeiros desmamados $(61,7 \mathrm{~kg} / \mathrm{ha})$ e diferiu significativamente $(\mathrm{P}=0,028)$ da observada nos piquetes com cordeiros e suas mães (13,3 kg/ha) e com cordeiros desmamados em creep feeding $(10,8 \mathrm{~kg} / \mathrm{ha})$. Esses resultados comprovaram o observado no pasto, pois, nos sistemas em que os cordeiros foram mantidos com as ovelhas, a quantidade de inflorescência foi menor, enquanto, no sistema com cordeiros desmamados, a quantidade era bem representativa, de modo que a pastagem apresentou aspecto bastante heterogêneo. Esse resultado indica variação no perfil da pastagem de acordo com a categoria animal utilizada. Segundo Carvalho et al. (2004b), em situações de valores elevados de massa de forragem, caracterizados por alta proporção de colmo e de material morto e/ou desenvolvimento reprodutivo (baixo valor nutritivo), os animais passam a explorar sítios de pastejo com massa de forragem menor que a média da pastagem, assegurando ingestão de forragem de melhor qualidade. Nesse processo, as áreas menos atraentes são menos exploradas e uma condição de mosaico heterogêneo, formado por regiões com forragem alta e forragem baixa, se estabelece, fato normalmente relacionado a maiores perdas de forragem no pastejo.

As condições climáticas foram extremamente desfavoráveis durante o mês de setembro e o início do mês de outubro. Nesta época ocorreu grande estiagem na região de Curitiba, com precipitação pluviométrica de 1,78 mm, segundo dados do Sistema Meteorológico do Paraná (SIMEPAR). Nos meses de escassez de chuvas, a massa seca média de folhas não ultrapassou $570 \mathrm{~kg} / \mathrm{ha}$, com redução de $30 \mathrm{~cm}$ para $10 \mathrm{~cm}$ na altura da pastagem. No período de setembro a dezembro, a relação folha:caule atingiu valores bastante reduzidos, chegando a 0,2 em setembro, com intensa diminuição na massa de azevém, que, no início do experimento (1.897 kg/ha), perfazia 72,5\% do total de forragem, e atingiu 13\% do total no final de outubro. Assim, a menor proporção de lâminas foliares de azevém pode ter reduzido a qualidade da dieta, prejudicando o desempenho dos cordeiros que só tinham a pastagem como fonte de alimento. A partir do final de outubro, a pastagem retomou a proporção de folhas, que elevou até janeiro, com recuperação da massa de forragem com a presença e pasto de tifton 85 (Figuras 1a, 1b e 1c).

A quantidade de colmos na pastagem das áreas apenas com cordeiros foi bastante elevada nos meses de setembro a dezembro (Figuras 1a, 1b e 1c), embora a relação folha:colmo média não tenha diferido significativamente entre os sistemas de terminação. Esse resultado reforça a hipótese de que os cordeiros selecionavam lâminas foliares (material de melhor qualidade) da pastagem. Nos sistemas em que as mães permaneceram com os cordeiros até o abate, houve menor seletividade no uso da forragem, uma vez que menor quantidade de colmos foi observada no período de utilização.

A altura média da pastagem (Tabela 1) foi maior $(\mathrm{P}=0,0044)$ nos sistemas com cordeiros desmamados $(20,95 \mathrm{~cm})$, provavelmente porque esses animais não conseguiam consumir toda a forragem disponível. No período de estiagem, a altura média dos três sistemas de terminação manteve-se entre 8 e $11 \mathrm{~cm}$. Carvalho et al. (2006), trabalhando com diversas alturas na pastagem de azevém, observaram que, na altura de $5 \mathrm{~cm}$, a cobertura da massa seca de forragem foi $1.416 \mathrm{~kg} / \mathrm{ha}$ e pode ter ocasionado, segundo esses autores, restrição ao consumo pelos animais. Neste trabalho, no período em que a altura chegou a $8 \mathrm{~cm}$, houve redução na massa de lâminas foliares disponíveis, que foi igual a $306,5 \mathrm{~kg} / \mathrm{ha}$, enquanto a de material morto foi igual a $1.632 \mathrm{~kg} / \mathrm{ha}$. Entretanto, a massa de forragem foi igual a $2.540 \mathrm{~kg} / \mathrm{ha}$, o que provavelmente não limitou o consumo de forragem pelos animais. A diminuição de folhas implicou aumento no tempo de pastejo, que passou de 50\% em 
(a) Cordeiros desmamados

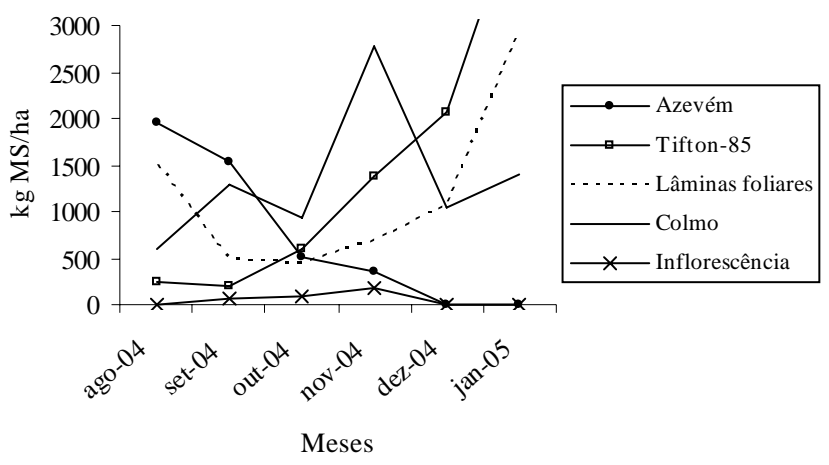

(b) Cordeiros sem desmame

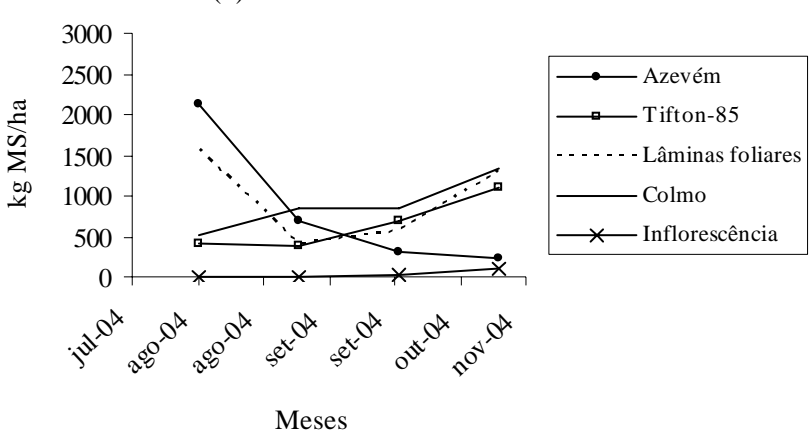

(c) Cordeiros em creep feeding

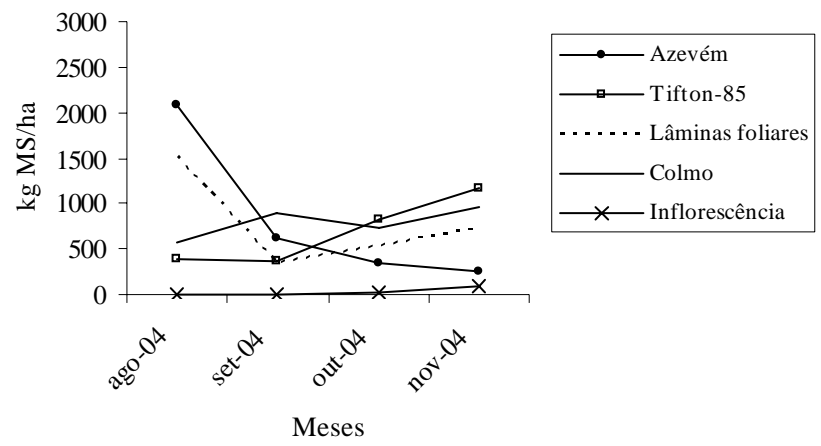

Figura 1 - Caracterização de pastagem de azevém utilizada por cordeiros em três sistemas de terminação.

Média dos sistemas no período de agosto/2004 a janeiro/2005. agosto para 64\% em setembro, pois os animais tiveram que selecionar mais a dieta. De acordo com Trevisan et al. (2004), baixos valores de biomassa de lâminas foliares afetam o comportamento ingestivo dos animais, forçando-os a aumentar o número de bocados e o tempo de pastejo como forma de melhorar o consumo de forragem, o que realmente ocorreu.

A taxa média de crescimento da pastagem foi de 58,38 kgMS/ha/dia e não diferiu entre os sistemas de terminação $(\mathrm{P}=0,651)$. O valor encontrado neste trabalho foi próximo aos descritos por Farinatti et al. (2006), 46,3 kg/ha de MS/dia, e Cauduro et al. (2006), 67,5 kg/ha de MS, em pastagem de azevém (Tabela 2).

A produção acumulada total de forragem não diferiu significativamente entre os sistemas de terminação $(\mathrm{P}=0,603)$ e apresentou valores próximos aos obtidos por Freitas et al. (2005) com novilhas, $6.801,3 \mathrm{~kg} / \mathrm{ha}$ de MS, e Frizzo et al. (2003) com bezerras em pastagem de aveia e azevém, 8.021 kg/ha de MS. O sistema de terminação com cordeiros desmamados apresentou valor bastante elevado (9.066,77 kg/ha de MS) em comparação ao dos cordeiros sem desmame, com ou sem creep feeding (Tabela 2), seguindo a mesma tendência da altura da pastagem e da massa de inflorescência do sistema com desmame. Esse valor superior pode estar relacionado ao maior número de cortes neste sistema, pois esses cordeiros demoram mais tempo para atingir o peso de abate.

A composição química da forragem (Tabela 3) não diferiu ( $P>0,05)$ entre os sistemas de terminação. Mesmo na época da estiagem, a qualidade da forragem colhida foi elevada (19\% PB, 28\% FDA e 70\% FDN), mas reduziu no período de reaparecimento de pasto de tifton 85 , com $15 \%$ PB, 35\% FDA e 82\% FDN (Figuras 2a, b, c).

Nos sistemas de produção em pastagens, são muito importantes as informações sobre a produtividade animal por área, que inclui o desempenho individual dos animais (Tabela 4). Nesse caso, o sistema de terminação no qual os

Tabela 2 - Taxa de crescimento e produção acumulada de forragem da pastagem de azevém utilizada por cordeiros em três sistemas de terminação

\begin{tabular}{|c|c|c|c|c|c|c|}
\hline Item & $\begin{array}{c}\text { Cordeiro } \\
\text { desmamado }\end{array}$ & $\begin{array}{c}\text { Erro-padrão } \\
\text { da média }\end{array}$ & $\begin{array}{c}\text { Cordeiro sem } \\
\text { desmame }\end{array}$ & $\begin{array}{c}\text { Erro-padrão } \\
\text { da média }\end{array}$ & $\begin{array}{l}\text { Cordeiro em } \\
\text { creep feeding }\end{array}$ & $\begin{array}{c}\text { Erro-padrão } \\
\text { da média } \\
\end{array}$ \\
\hline $\begin{array}{l}\text { Taxa de crescimento } \\
\text { (kgMS/ha/dia) }\end{array}$ & 65,54 & 14,73 & 47,50 & 18,52 & 62,11 & 6,085 \\
\hline $\begin{array}{l}\text { Produção acumulada de } \\
\text { forragem (kgMS/ha) }\end{array}$ & $9.066,77$ & $2.309,2$ & $6.285,09$ & $2.027,0$ & $7.625,52$ & $1.056,7$ \\
\hline
\end{tabular}


Tabela 3 - Composição química da pastagem de azevem utilizada por cordeiros em três sistemas de terminação

\begin{tabular}{|c|c|c|c|c|c|c|}
\hline Nutriente (\% MS) & $\begin{array}{c}\text { Cordeiro } \\
\text { desmamado }\end{array}$ & $\begin{array}{c}\text { Erro-padrão } \\
\text { da média }\end{array}$ & $\begin{array}{c}\text { Cordeiro sem } \\
\text { desmame }\end{array}$ & $\begin{array}{c}\text { Erro-padrão } \\
\text { da média }\end{array}$ & $\begin{array}{l}\text { Cordeiro em } \\
\text { creep feeding }\end{array}$ & $\begin{array}{c}\text { Erro-padrão } \\
\text { da média }\end{array}$ \\
\hline Proteína bruta (\%) & 19,58 & 0,404 & 19,68 & 0,334 & 20,01 & 0,531 \\
\hline Fibra em detergente neutro (\%) & 58,74 & 3,44 & 58,42 & 1,402 & 53,57 & 0,848 \\
\hline Cálcio (\%) & 0,70 & 0,028 & 0,71 & 0,017 & 0,76 & 0,011 \\
\hline Fósforo (\%) & 0,28 & 0,023 & 0,29 & 0,023 & 0,28 & 0,023 \\
\hline
\end{tabular}

(a) Proteína bruta

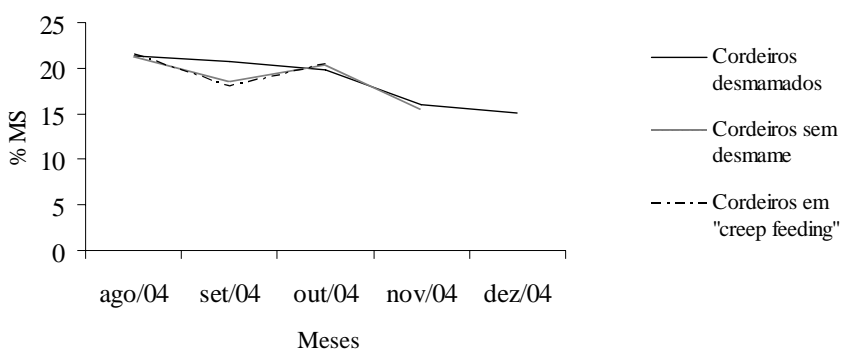

(b) Fibra de detergente ácido

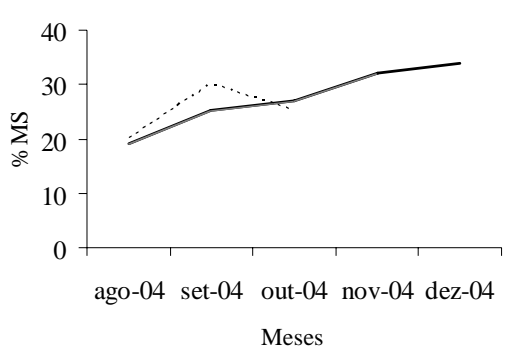

(c) Fibra de detergente neutro

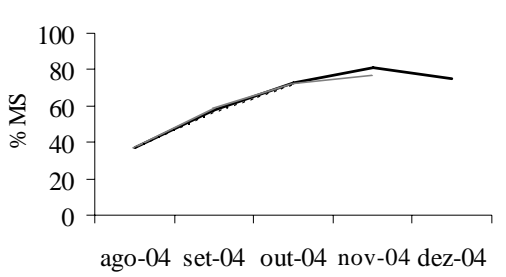

Meses

Figura 2 - Qualidade da pastagem de azevém utilizada por cordeiros em três sistemas de terminação. cordeiros foram desmamados e terminados em azevém permitiu maior $(\mathrm{P}=0,000001)$ carga de cordeiros por área (929,74 kg PV/ha), uma vez que o número de cordeiros era maior. Nos cálculos, foram considerados apenas os pesos de cordeiros. Apesar de o sistema com cordeiros desmamados ter apresentado maior carga animal, os animais desse sistema apresentaram o menor desempenho individual (0,115 kg/dia) e maior idade ao abate (159 dias) em comparação aqueles do sistema sem desmame, sem e com creep feeding (0,303 kg/dia; 105 dias versus 0,294 kg/dia; 106 dias), respectivamente. De acordo com Hodgson (1990), altas cargas animais não são compatíveis com elevados desempenhos individuais dos animais, o que ficou evidenciado neste experimento.

Calculando a carga animal de cordeiros mais ovelhas (carga animal total), obteve-se 808,84 kg PV/ha e 754,13kg $\mathrm{PV} /$ ha para cordeiros sem suplementação e cordeiros em creep feeding, respectivamente, sem diferença significativa $(\mathrm{P}=0,65)$.

Farinatti et al. (2006) observaram que animais sob suplementação reduziram o consumo de forragem, possibilitando maior carga animal por hectare e maior ganho por área, o que não foi evidenciado neste estudo.

No Rio Grande do Sul, Farinatti et al. (2006) encontraram 130,9 kg PV/ha em pesquisa com ovelhas e cordeiros e considerando apenas as cordeiras ao pé das mães em pastagem de azevém, enquanto Pontes et al. (2004), em experimentos com cordeiros de 12 meses e $36 \mathrm{~kg}$ de peso vivo inicial, obtiveram carga animal de $2.036 \mathrm{~kg} / \mathrm{ha}$ a $1.033 \mathrm{~kg}$ PV/ha na altura de pasto de 5 a $20 \mathrm{~cm}$. Assim,

Tabela 4 - Lotação animal (número de cordeiros e ovelhas/área), carga animal (cordeiros e cordeiros+ovelhas; kg PV/ha) e ganho de peso vivo por área por dia (kg PV/ha/dia) de cordeiros e ovelhas em três sistemas de terminação

\begin{tabular}{|c|c|c|c|c|c|c|}
\hline Item & $\begin{array}{c}\text { Cordeiro } \\
\text { desmamado }\end{array}$ & $\begin{array}{l}\text { Erro-padrão } \\
\text { da média }\end{array}$ & $\begin{array}{c}\text { Cordeiro sem } \\
\text { desmame }\end{array}$ & $\begin{array}{c}\text { Erro-padrão } \\
\text { da média }\end{array}$ & $\begin{array}{l}\text { Cordeiro em } \\
\text { creep feeding }\end{array}$ & $\begin{array}{c}\text { Erro-padrão } \\
\text { da média }\end{array}$ \\
\hline Lotação - cordeiros/ha & $31,47 \mathrm{a}$ & 3,698 & $8,36 b$ & 0,456 & $8,84 b$ & 0,848 \\
\hline kg PV cordeiros/ha & $929,74 a$ & 7,99 & $259,96 b$ & 16,58 & $254,37 b$ & 8,371 \\
\hline kg PV cordeiros + ovelhas/ha & - & - & 808,84 & 56,57 & 754,13 & 33,92 \\
\hline Ganho/ha/dia & 3,46 & 0,727 & 2,19 & 0,138 & 2,52 & 0,386 \\
\hline
\end{tabular}

Médias seguidas de letras diferentes na mesma linha diferem $(\mathrm{P}<0,05)$ pelo teste Duncan. 
pode-se inferir que a carga animal obtida foi próxima à descrita na literatura para ovinos em pastejo, em ambiente subtropical.

Neste estudo, os cordeiros dos três sistemas não diferiram em ganho/área/dia.

O número de cordeiros por área foi maior $(\mathrm{P}=0,0007)$ nos animais desmamados $(31,47)$ em comparação aos demais, sem $(8,36)$ e com suplementação $(8,84)$. Essa diferença na lotação logicamente se apóia no fato de que a área era ocupada apenas por essa categoria animal no primeiro caso. Os sistemas sem desmame, além dos cordeiros, oito animais em média, mantinham ainda seis ovelhas no pasto, totalizando 14 animais/ha.

Na literatura, Siqueira et al. (1993) afirmam que o desmame é necessário pelo fato de que a permanência dos cordeiros com as mães no pasto até o abate pode levar à elevada contaminação dos cordeiros, em virtude da contaminação das pastagens pelas ovelhas. Nesse caso, o controle parasitário no sistema em que os cordeiros permaneceram com suas mães manteve-se dentro do esperado, sem nenhum caso de anemia intensa ou óbito, o que não confirma esta afirmação.

Assim, os sistemas sem desmame, apesar da carga animal (kg PV cordeiros/ha) inferior, uma vez que as ovelhas estavam presentes, permitiu melhor condição nutricional aos cordeiros, provavelmente conferindo-lhes maior imunidade e diminuindo a ocorrência de helmintoses. Por outro lado, o mesmo sistema não possibilitaria a liberação das ovelhas para áreas de pastagem de disponibilidade e qualidade inferior, como indicado para ovelhas secas e em mantença (NRC, 1985). Além disso, dificultaria a obtenção de estação de monta antecipada fora da época convencional de verão/outono, utilizada nas propriedades com sistema acelerado de parição com três partos em dois anos, uma vez que o período de lactação das mães é prolongado, pois as ovelhas permanecem junto aos cordeiros até o abate, próximo dos 100 dias.

\section{Conclusões}

As características estruturais da pastagem foram alteradas pelos sistemas de produção, em virtude da maior seletividade do consumo dos cordeiros sem o pastejo das ovelhas. Os sistemas de terminação não influenciaram a qualidade da forragem colhida pelos cordeiros em pastejo, o que indica atendimento das necessidades nutricionais dos animais. A carga animal por área foi maior nos sistemas com desmame, porém, a produtividade nesses sistemas foi menor, em razão do baixo desempenho individual dos cordeiros, assim o sistema de terminação em pastagem com desmame precoce não deve ser recomendado a ovinocultores.

\section{Agradecimentos}

À CAPES, pela concessão de bolsa de estudo; ao CNPq, pelo auxílio financeiro para execução do projeto; e à Fazenda experimental do Cangüiri, pela cessão dos animais e das instalações e pelo apoio.

\section{Literatura Citada}

BARTHRAM, G.T. Experimental techniques: the HFRO sward stick. Biennal Report 1984-1985. Hill Farming Research Organization, Penicuik, 1986. p.29-30.

BRISKE, D.D.; HEITSCHMIDT, R.K. Ecological perspective. In: HEITSCHMIDT, R.K.; STUTH, J.W. (Eds.). Grazing management: an ecological perspective. Oregon: Timber Press, 1991. p.11-26.

BURMS, J.C.; LIPPKE, H.; FISHER, D.S. The relationship of herbage mass and characteristics to animal responses in grazing experiments. In: MARTEN, G.C. (Ed.) Grazing research: design, methodology and analysis. Madison: Crop Science Society of America, 1989. p7-20.

CARVALHO, P.C.F.; MORLAN, J.B.; CONDORELLI, E.M. et al Práticas em ovinocultura: ferramentas para o sucesso. Porto Alegre: SENAR-RS, 2004a. 146p.

CARVALHO, P.C.F.; CANTO, M.W.; MORAES, A. Fontes de perdas de forragem sob pastejo: forragem se perde?. In: PEREIRA, O.G.; OBEID, J.A.; FONSECA, D.M.; NASCIMENTO JR., D. (Eds.). Manejo estratégico da pastagem. 1.ed. Viçosa, MG: Suprema Gráfica e Editora, 2004b. v.1, p.387-418.

CARVALHO, P.C.F.; OLIVEIRA, J.O.R.; PONTES, L.S. et al. características de carcaças de cordeiros em pastagem de azevém manejada em diferentes alturas. Pesquisa Agropecuária Brasileira, v.41, n.7, p.1193-1198, 2006.

CAUDURO, G.F.; CARVALHO, P.C.F.; BARBOSA, C.M.P. et al. Variáveis morfogênicas e estruturais de azevém (Lolium multiflorum Lam.) manejada sob diferentes intensidades e métodos de pastejo. Revista Brasileira de Zootecnia, v.35, n.4, p.1298-1307, 2006.

EMPRESA BRASILEIRA DE PESQUISA E AGROPECUÁRIA EMBRAPA Sistema brasileiro de classificação de solos. Brasília: Centro Nacional de Pesquisa de Solos, 1999. 412p. (Documentos, 5).

FARINATTI, L.H.E.; ROCHA, M.G.; POLI, C.H.E.C. et al. Desempenho de ovinos recebendo suplementos ou mantidos exclusivamente em pastagem de azevém (Lolium multiflorum Lam.). Revista Brasileira de Zootecnia, v.35, n.2, p.527-534, 2006.

FERREIRA, D.J.; ZANINE, A.M. Importância da pastagem cultivada na produção da pecuária de corte brasileira. Revista Eletrônica de Veterinária, v.8, n.3, p.1-18, 2007.

FREITAS, F.K.; ROCHA, M.G.; BRONDANI, I.L. et al. Suplementação energética na recria de fêmeas de corte em pastagem cultivada e inverno. Dinâmica da pastagem. Revista Brasileira de Zootecnia, v.34, n.6, p.2029-2038, 2005.

FRIZZO, A.; ROCHA, M.G.; RESTLE, J. et al. Massa de forragem e retorno econômico da pastagem de aveia e azevém sob pastejo com bezerras de corte submetidas a níveis de suplementação energética. Revista Brasileira de Zootecnia, v.32, n.3, p.632-642, 2003.

HODGSON, J. Grazing management: science into practice. Longman Handbooks in Agriculture. New York: John Wiley \& Sons, 1990. 203p. 
KEARL, L.C. Nutrient requirements of ruminants in developing countries. International Feedstuff Institute. Logan: Utah State University, 1982. 381p.

MORAES, A.; MOOJEN, E.L.; MARASCHIN, G.E. Comparação de métodos de taxas de crescimento em uma pastagem submetida a diferentes pressões de pastejo. In: REUNIÃO ANUAL DA SOCIEDADE BRASILEIRA DE ZOOTECNIA, 27., 1990, Campinas. Anais... Campinas: Sociedade Brasileira de Zootecnia, 1990. p.332.

MOTT, G.O.; LUCAS, H.L. The design, conduct and interpretation of grazing trials on cultivated and improved pastures. In: INTERNATIONAL GRASSLAND CONGREES, 6., 1952, State College. Proceedings...State College: Pensylvania State College Press, 1952. p.1380-1385.

NATIONAL RESEARCH COUNCIL - NRC. Nutrient requirements of sheep. Washington, D.C.: National Academy Press, 1985. p.99.

PEDREIRA, C.G.S.; PEDREIRA, B.C.; TONATO, F. Quantificação da massa e da produção de forragem em pastagens. In: Fundação de Estudos Agrários. (Ed.). Teoria e prática da produção animal em pastagens. Piracicaba: Fundação de Estudos Agrários, 2005. p.195-216.

PONTES, L.S.; CARVALHO, P.C.F.; NABINGER, C. et al. Fluxo de biomassa em pastagens de azevém anual (Lolium multiflorum Lam) manejadas em diferentes alturas. Revista Brasileira de Zootecnia, v.33, n.3, p.529-537, 2004.

SILVA, D.J. Análise de alimentos: métodos químicos e biológicos. Viçosa, MG: Universidade Federal de Viçosa, 1990. 165p.

SIQUEIRA, E.R.; AMARANTE, A.F.T.; FERNANDES, S. Estudo comparativo da recria de cordeiros em confinamento e pastagem. Veterinária e Zootecnia, v.5, p.9-19, 1993.

TREVISAN, N.B.; QUADROS, F.L.F.; SILVA, A.C.F. et al. Comportamento ingestivo de novilhos de corte em pastagem de aveia preta e azevém com níveis distintos de folhas verdes. Ciência Rural, v.34, n.5, p.1543-1548, 2004.

Van SOEST, P.J.; ROBERTSON, J.B.; LEWIS, B.A. Methods for dietary fiber, and no starch polysaccharides in relation animal nutrition. Journal of Dairy Science, v.74, n.10, p.3583-3587, 1991 